\title{
Produção de matéria seca e controle de plantas daninhas por leguminosas consorciadas com cana-de-açúcar em cultivo orgânico
}

\author{
Raíssa de Araujo Dantas( ${ }^{(1)}$, Ricardo Carmona(1), Arminda Moreira de Carvalho(2), \\ Thomaz Adolpho Rein ${ }^{(2)}$, Juaci Vitoria Malaquias ${ }^{(2)}$ e João de Deus Gomes dos Santos Júnior ${ }^{(2)}$
}

(1)Universidade de Brasília, Faculdade de Agronomia e Medicina Veterinária, Caixa Postal 4508, CEP $70910-970$ Brasília, DF, Brasil.
E-mail: rahdantas08@gmail.com, rcarmona@unb.br (2)Embrapa Cerrados, Caixa Postal 08223, CEP 73301-970 Planaltina, DF, Brasil.
E-mail: arminda.carvalho@embrapa.br, thomaz.rein@embrapa.br, juaci.malaquias@embrapa.br, joao.jr@embrapa.br

Resumo - O objetivo deste trabalho foi avaliar a produção de matéria seca e o controle de plantas daninhas por espécies de leguminosas consorciadas com cana-de-açúcar, em cultivo orgânico. As espécies leguminosas Arachis pintoi, Cajanus cajan, Calopogonium mucunoides, Crotalaria anagyroides, Crotalaria juncea e Stylosanthes 'Campo Grande' foram semeadas em novembro de 2012, nas entrelinhas da cana-de-açúcar. $\mathrm{O}$ delineamento experimental em blocos ao acaso foi utilizado com quatro repetições e dois controles - um tratamento capinado e outro sem capinar. A massa de matéria seca das leguminosas foi avaliada aos 142 dias após a semeadura (DAS), e a massa de matéria seca de plantas daninhas, aos 29, 85 e 142 DAS. A massa de matéria seca de plantas daninhas foi inferior à da testemunha em todas as épocas amostradas. A produção de massa de matéria seca das leguminosas no consórcio foi baixa. As espécies Crotalaria juncea, Cajanus cajan e Calopogonium mucunoides produziram massa de matéria seca superior à das espécies Arachis pintoi e Stylosanthes 'Campo Grande'. A produtividade de colmos da cana-de-açúcar não foi afetada pelo consórcio. O consórcio entre cana-de-açúcar orgânica e leguminosas com semeadura tardia, para adubação verde, é eficiente no controle de plantas daninhas.

Termos para indexação: Saccharum, açúcar orgânico, adubo verde, manejo cultural, planta de cobertura.

\section{Dry matter production and weed control by intercropped legumes with sugarcane in organic cropping}

\begin{abstract}
The objective of this work was to evaluate dry matter production and weed control by intercropped legumes with sugarcane, in organic cropping. The legume species Arachis pintoi, Cajanus cajan, Calopogonium mucunoides, Crotalaria anagyroides, Crotalaria juncea, and Stylosanthes 'Campo Grande' were sown on November 2012 in the inter-rows of sugarcane. A randomized complete block experimental design was used with four replicates and two controls - a weeded treatment and an unweeded one. Legume dry matter was evaluated 142 days after sowing (DAS), and the weed dry matter, at 29, 85, and 142 DAS. Weed dry matter was lower than that of the control in all sampling periods. The production of legume dry matter was low in intercropping. The species Crotalaria juncea, Cajanus cajan, and Calopogonium mucunoides produced higher dry matter than the species Arachis pintoi and Stylosanthes 'Campo Grande'. Stalk yield of sugarcane was not affected by intercropping. The intercropping of organic sugarcane and legumes in late sowing, for green manure, is efficient for weed control.
\end{abstract}

Index terms: Saccharum, organic sugar, green manure, crop management, cover crop.

\section{Introdução}

A cultura da cana-de-açúcar figura entre as mais importantes da economia do Brasil, que, atualmente, é o maior produtor no mundo. A produção brasileira foi superior a 730 milhões de toneladas de colmos no ano de 2013, e a área plantada cresceu 51\% entre 2002 e 2013 (Instituto Brasileiro de Geografia e Estatística, 2013). Dentre os segmentos do setor sucroenergético, destaca-se a produção orgânica de cana-de-açúcar. A adoção desse sistema de manejo é justificada pelos benefícios socioambientais, pela exigência do mercado consumidor quanto à segurança alimentar e pelo retorno econômico do cultivo do açúcar orgânico para o produtor (Storel Júnior, 2003).

Todavia, alguns entraves são enfrentados no cultivo orgânico de cana-de-açúcar, como o controle de plantas daninhas, em razão da proibição do uso de herbicidas 
nesse tipo de produção agrícola. A infestação de plantas daninhas pode provocar efeitos negativos na cultura, como a redução do perfilhamento e da produtividade de colmos e sacarose, decréscimo da longevidade do canavial, queda da qualidade da matéria-prima e dificuldade nas operações de colheita e transporte (Kuva et al., 2003).

Assim, a utilização de leguminosas como adubo verde, no manejo de plantas daninhas, surge como alternativa no sistema orgânico de produção. O potencial das leguminosas no controle cultural de espécies invasoras é descrito na literatura (Fernandes et al., 1999; Severino \& Christoffoleti, 2001; Erasmo et al., 2004; Monquero et al., 2009).

Na cadeia produtiva de cana-de-açúcar, essa prática é largamente utilizada tanto em sistema orgânico como em convencional, na ocasião da reforma do canavial e antes do plantio da cana de ano e meio, o que proporciona, além da redução da incidência de plantas daninhas, incrementos na produtividade da cultura comercial e melhoria das características físicas, químicas e biológicas do solo (Nixon \& Simmonds, 2004).

O consórcio entre cana-de-açúcar e leguminosas, porém, é ainda pouco estudado. Alguns autores descreveram os efeitos dessa prática sobre a incidência de plantas daninhas e sobre a interferência com o desenvolvimento da cana-de-açúcar. Singh \& Lal (2008) verificaram que o cultivo consorciado de cana-de-açúcar com espécies do gênero Vigna apresentou reduções significativas da densidade e acúmulo de massa de matéria seca de plantas daninhas. Além disso, o consórcio não interferiu no crescimento nem na produtividade da cultura e nos parâmetros de qualidade do caldo, em comparação à testemunha.

Diversos autores constataram os efeitos das leguminosas sobre a produtividade de colmos em sistemas de consórcio. Resende et al. (2003) e Ambrosano et al. (2013) verificaram que Crotalaria juncea pode reduzir a produtividade de colmos, quando consorciada com cana-de-açúcar. Yang et al. (2013) avaliaram o consórcio entre a cana-de-açúcar e a soja e constataram que a soja reduziu a produtividade da cana-de-açúcar. Contudo, Li et al. (2013) observaram benefícios do sistema de consorciação entre cana-de-açúcar e soja, em que houve aumento da produtividade de colmos.
O objetivo deste trabalho foi avaliar a produção de matéria seca e o controle de plantas daninhas por espécies de leguminosas consorciadas com cana-de-açúcar, em cultivo orgânico.

\section{Material e Métodos}

O experimento foi realizado em parte de talhão comercial de cana-de-açúcar em manejo orgânico, na usina Goiasa, em Goiatuba, GO, a $18^{\circ} 0^{\prime} 5^{\prime \prime} \mathrm{S}$, 49 44'22" W, à altitude de $651 \mathrm{~m}$. O clima da região é classificado como Aw (Köppen), com duas estações bem definidas (seca e chuvosa), com possibilidade de ocorrência de veranicos (Figura 1).

O relevo caracteriza-se como suave-ondulado, a vegetação original é de Cerrado, e o solo é classificado como Latossolo Vermelho distrófico (Santos et al., 2013). A análise química da camada de 0-20 cm do solo da área experimental apresentou os seguintes resultados: $\mathrm{pH}$ em água, 7,0; $\mathrm{P}$ (Mehlich 1), 2,18 $\mathrm{mg} \mathrm{dm}^{-3} ; \mathrm{K}, 152 \mathrm{mg} \mathrm{dm}^{-3} ; \mathrm{Ca}, 3,7 \mathrm{cmol}_{\mathrm{c}} \mathrm{dm}^{-3} ; \mathrm{Mg}$, $1,58 \mathrm{cmol}_{\mathrm{c}} \mathrm{dm}^{-3} ; \mathrm{Al}, 0,02 \mathrm{cmol}_{\mathrm{c}} \mathrm{dm}^{-3}$.

As operações de preparo do solo para o plantio da cana-de-açúcar, realizadas em agosto de 2011, incluíram subsolagem, seguida de gradagem pesada. Posteriormente, nos meses de setembro e outubro de 2011, foram realizadas duas operações com grade intermediária. Um mês antes do plantio da Crotalaria spectabilis, foi realizada uma operação com grade niveladora.

Em dezembro de 2011, $10 \mathrm{~kg} \mathrm{ha}^{-1}$ de sementes de Crotalaria spectabilis foram semeadas, a lanço, na área total do talhão (476,7 ha). A leguminosa foi incorporada com grade niveladora ao solo, 140 dias após a semeadura, no início do florescimento (antes do enchimento das vagens).

A cana-de-açúcar foi plantada na área total do talhão em março de 2012, e a variedade utilizada foi a 'SP86-155'. Utilizaram-se toletes produzidos na própria usina. A profundidade do sulco foi de $30 \mathrm{~cm}$, e o espaçamento entre linhas de $1,5 \mathrm{~m}$.

Em seguida, a cultura foi adubada em cobertura, na linha de plantio, com $18,6 \mathrm{Mg} \mathrm{ha}^{-1}$ de composto orgânico (torta de filtro e cinzas de caldeira) e $300 \mathrm{~m}^{3} \mathrm{ha}^{-1}$ de vinhaça, aplicados por canhão de propulsão. Sessenta dias após o plantio, realizou-se a operação de "quebra-lombo", que significa retornar o solo das entrelinhas para o sulco de plantio. 
No início de novembro de 2012, período escolhido em razão da ocorrência de chuvas na região, foram semeadas duas linhas de leguminosas nas entrelinhas da cana-de-açúcar. As espécies utilizadas foram: amendoim forrageiro 'Amarillo' (Arachis pintoi), calopogônio (Calopogonium mucunoides), xiquexique (Crotalaria anagyroides), crotalária júncea (Crotalaria juncea), estilosantes 'Campo Grande' (mistura física de sementes de Stylosanthes capitata e S. macrocephala) e guandu-anão (Cajanus cajan). As sementes das leguminosas provieram da coleção de adubos verdes da Embrapa Cerrados, à exceção das sementes de amendoim forrageiro e estilosantes 'Campo Grande', que foram adquiridas comercialmente.

Utilizou-se o delineamento experimental em blocos ao acaso, com oito tratamentos e quatro repetições, em que os tratamentos são representados pelas seis leguminosas cultivadas em consórcio, testemunha com capina e sem leguminosa e testemunha sem capina e sem leguminosa. As dimensões das parcelas experimentais foram de 7,5 x $15 \mathrm{~m}$, no total de $112,5 \mathrm{~m}^{2}$ de área, e com cinco linhas de cana-de-açúcar e dez linhas de leguminosas. A área total do experimento foi de 1.031,2 $\mathrm{m}^{2}$, considerando-se os carreadores.

Antes da semeadura, realizou-se o teste de germinação das sementes de leguminosas, tendo-se considerado o valor da percentagem de germinação no cálculo de sementes por metro linear. Para sementes de calopogônio, procedeu-se à escarificação com ácido sulfúrico $\left(\mathrm{H}_{2} \mathrm{SO}_{4}\right)$ a $100 \%$ por $10 \mathrm{~min}$. As sementes de todas as espécies, à exceção de estilosantes, que nodula eficientemente com estirpes nativas, receberam inoculação de inoculante específico, obtido do Laboratório de Microbiologia dos Solos da Embrapa Cerrados. Utilizou-se um coquetel das estirpes de rizóbio CPAC C2, CPAC B10 e CPAC P2. A inoculação foi realizada na noite anterior à semeadura, à proporção de $1 \mathrm{~kg}$ de inoculante para $25 \mathrm{~kg}$ de sementes, tendose empregado solução de água com açúcar a $10 \%$, para adesão do inoculante turfoso às sementes. Para melhor uniformidade da semeadura, misturou-se areia fina às sementes de calopogônio e estilosantes 'Campo Grande', em razão do tamanho reduzido das sementes. A sulcagem do solo e a semeadura das espécies leguminosas foram realizados manualmente, com auxílio de enxadas, para sulcos mais profundos, e de estacas de madeira pontiagudas, para sulcos mais rasos. O espaçamento entre as duas linhas semeadas foi de $0,5 \mathrm{~m}$ para todas as espécies, que assim distaram $0,5 \mathrm{~m}$ das linhas de cana.

As plantas daninhas da área experimental foram amostradas nos tratamentos e na testemunha sem capina e sem leguminosa, para avaliação da massa de matéria seca de plantas daninhas, por hectare, em três períodos: 29, 85 e 142 dias após a semeadura das leguminosas (DAS).

A amostragem das plantas daninhas nas parcelas foi realizada com auxílio de um retângulo de ferro, com $43,5 \times 28 \mathrm{~cm}\left(0,12 \mathrm{~m}^{2}\right.$ de área), que foi posicionado na porção central da parcela (duas entrelinhas centrais).

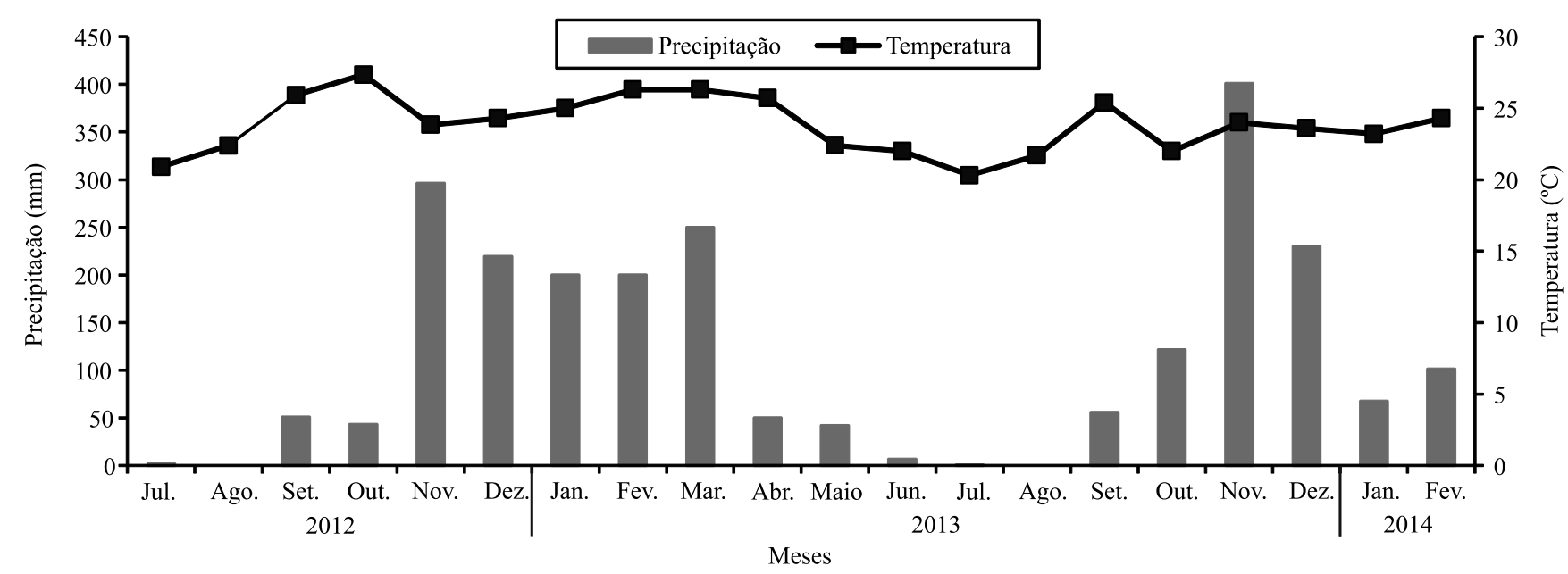

Figura 1. Precipitação pluvial acumulada e temperatura média mensal na área de plantio, durante período de condução do experimento em Goiatuba, GO. Fonte: Sistema... (2014). 
A amostragem foi realizada quatro vezes em cada parcela e em pontos distintos. Esse posicionamento foi alterado também em cada período de avaliação, e não se repetiu o local anteriormente amostrado. As plantas contidas no retângulo foram coletadas, depositadas em sacos de papel e colocadas em estufa de ventilação forçada a $65^{\circ} \mathrm{C}$, por 72 horas, até que atingissem massa constante $\mathrm{e}$, em seguida, foram pesadas.

Aos 142 dias após a semeadura, as leguminosas foram cortadas rente ao solo, nas quatro linhas de leguminosas por parcela, escolhidas ao acaso, com comprimento de um metro cada, para quantificação da massa de matéria seca. As amostras coletadas foram depositadas em sacos de papel e colocadas em estufa de ventilação forçada a $65^{\circ} \mathrm{C}$, por 72 horas, até que atingissem massa constante e, em seguida, foram pesadas. A colheita da cana-de-açúcar foi realizada na primeira quinzena de junho de 2013 , em que foram marcados os $6 \mathrm{~m}$ centrais de cada uma das três linhas de plantas centrais. Em seguida, procedeu-se à colheita manual, tendo-se cortado a base da cana, retirado a ponteira (desponte da cana) e depois enleirado os colmos na extremidade de cada parcela. Após a despalha, os colmos foram pesados para cálculo de produtividade, com auxílio de balança de dinamômetro com capacidade de $200 \mathrm{~kg}$ e precisão de $100 \mathrm{~g}$ (Kern \& Sohn GmbH, Balingen, Alemanha), e a colheita do restante do experimento foi mecanizada.

Das leiras de colmos colhidos manualmente, retirou-se uma subamostra de dez colmos obtidos ao acaso. As subamostras foram enviadas ao laboratório de análises de qualidade de cana-de-açúcar da Usina Goiasa, onde foram obtidos dados de grau Brix, teor de fibras, pureza do caldo, POL da cana e produção de açúcar, segundo metodologia descrita pelo Conselho dos Produtores de Cana-de-Açúcar, Açúcar e Álcool do Estado de São Paulo (2006). A amostragem e a análise tecnológica foram realizadas nos colmos de cana-planta e nos colmos de primeira soca.

Após a colheita, a primeira soqueira foi adubada com $14 \mathrm{t} \mathrm{ha}^{-1}$ de composto orgânico (torta de filtro e cinzas de caldeira) em cobertura na linha de plantio e foram aplicados $300 \mathrm{~m}^{3} \mathrm{ha}^{-1}$ de vinhaça por canhão de propulsão, com subsequente repasse de $183,4 \mathrm{~m}^{3} \mathrm{ha}^{-1}$ de vinhaça no fim de outubro de 2013. A colheita da primeira soca foi realizada no final de maio de 2014 e os mesmos procedimentos para colheita e amostragem da cana-planta foram adotados.
Para a análise estatística dos dados de massa de matéria seca de leguminosas foi realizada transformação pela equação $\mathrm{y}=\log (\mathrm{x})$, em que: $\mathrm{y}$ é o valor transformado da massa de matéria seca de leguminosas; e x é o valor amostrado da massa de matéria seca de leguminosas.

Para os dados de massa de matéria seca de plantas daninhas, aos 29 DAS, realizou-se a transformação estabilizadora da variância, pelo procedimento REG (Procreg) do SAS 9.2 (SAS Institute, Cary, NC, EUA), com o objetivo de atender aos pressupostos da análise de variância (normalidade, homogeneidade e independência dos resíduos). A transformação foi realizada com base na regressão linear $\log \left(\sigma^{2}\right)=\log \beta+\alpha \log \mu$, entre o logaritmo da variância e o logaritmo da média. Assim, os dados de massa de matéria seca de plantas daninhas aos 29 DAS foram transformados pela equação $\mathrm{y}=\mathrm{x}^{\alpha}$, em que: $\mathrm{y}$ é o valor transformado da massa de matéria seca de plantas daninhas; e x é o valor amostrado da massa de matéria seca de plantas daninhas por hectare.

Para os dados de massa de matéria seca de plantas daninhas aos 85 e 142 DAS, assim como da produtividade da cultura, produção de açúcar e parâmetros de qualidade, utilizaram-se dados não transformados.

Nas três avaliações de massa de matéria seca de plantas daninhas $(29,85$ e 142 DAS), desconsideraramse os valores aberrantes ou atípicos (outliers), com o auxílio da estatística descritiva por meio de gráficos boxplot.

A análise de variância pelo procedimento foi aplicada, com comparação de médias pelo teste de Duncan, a $5 \%$ de probabilidade, exceto na avaliação aos 142 DAS, em que o procedimento não paramétrico de Kruskal-Wallis e o teste Wilcoxon-Mann-Whitney foram aplicados a $5 \%$ de probabilidade (PROC NPAR1WAY), pelo fato de os dados apresentarem distribuição de probabilidade diferente da distribuição normal, mesmo quando transformados.

\section{Resultados e Discussão}

Houve diferenças significativas na produção de massa de matéria seca das leguminosas consorciadas, quantificada aos 142 DAS (Tabela 1). As espécies Cajanus cajan, Calopogonium mucunoides e Crotalaria juncea produziram massa de matéria seca superior à das demais espécies testadas. Todavia, a produção de 
massa de matéria seca de todas as leguminosas testadas foi inferior ao cultivo solteiro.

Ambrosano et al. (2013), em experimento semelhante, constataram produções de 1,0 e 2,8 $\mathrm{Mg} \mathrm{ha}^{-1}$ de massa de matéria seca de Cajanus cajan e, Crotalaria juncea, respectivamente. Porém, quando semeadas em monocultura no início do período chuvoso, estas espécies podem acumular até 8,7 e $17 \mathrm{Mg} \mathrm{ha}^{-1}$, respectivamente (Amabile et al., 2000; Pereira et al., 2012).

Entretanto, Prellwitz \& Coelho (2011) avaliaram o consórcio entre a cana-soca e Crotalaria juncea e obtiveram massa de matéria seca mais expressiva dessa leguminosa do que a obtida no presente trabalho, com acúmulo que variou, conforme a densidade e época de plantio da leguminosa, de 2,2 a 9,0 $\mathrm{Mg} \mathrm{ha}^{-1}$.

O gênero Stylosanthes, nativo da flora brasileira, apesar de se destacar pela ampla adaptação e resistência às pressões bióticas e abióticas (Barcellos et al., 2008), apresentou baixo rendimento de massa de matéria seca nas condições deste experimento, em razão do ciclo de desenvolvimento mais lento, com florescimento entre abril e maio (Cultivo..., 2007), e ficou em desvantagem no sistema de consorciação com relação às demais espécies testadas. Observou-se, portanto, que a interferência negativa da cana-de-açúcar no estabelecimento de Stylosanthes 'Campo Grande' foi superior à interferência nas espécies de crescimento inicial rápido, como Crotalaria juncea e Cajanus cajan.

Santos et al. (2011) também constataram efeitos da competição interespecífica, em sistemas de consórcio

Tabela 1. Massa de matéria seca da parte aérea de leguminosas adubos verdes, semeadas nas entrelinhas da cana-de-açúcar, cortadas aos 142 dias após a semeadura ${ }^{(1)}$.

\begin{tabular}{lc}
\hline Espécies & $\begin{array}{c}\text { Massa de matéria seca } \\
\left(\mathrm{kg} \mathrm{ha}^{-1}\right)\end{array}$ \\
\hline Arachis pintoi & $32,5 \mathrm{c}$ \\
Cajanus cajan & $795,0 \mathrm{a}$ \\
Calopogonium mucunoides & $625,0 \mathrm{a}$ \\
Crotalaria anagyroides $^{(2)}$ & - \\
Crotalaria juncea $_{\text {Stylosanthes 'Campo Grande' }}$ & $852,5 \mathrm{a}$ \\
\hline CV (\%) & $97,5 \mathrm{~b}$ \\
\hline
\end{tabular}

${ }^{(1)}$ Médias seguidas por letras iguais não diferem entre si, pelo teste de Duncan, a 5\% de probabilidade. ${ }^{(2)}$ Aos 142 dias após a semeadura, Crotalaria anagyroides não sobreviveu ao ataque de doença fúngica causada por $\mathrm{Col}$ letotrichum crotalariae. entre gramíneas e Stylosanthes 'Campo Grande'. A leguminosa, quando semeada simultaneamente com Panicum maximum 'Mombaça' e Panicum maximum 'Tanzânia', acumulou massa de matéria seca inferior a $20 \%$ do total produzido no consórcio com as duas espécies.

Aprodução de massa de matéria seca de Arachis pintoi foi inferior à das demais espécies, em consequência do ataque de formigas logo após a germinação, entre outros fatores. Por se tratar de área de produção orgânica, a incidência de formigas-cortadeiras é elevada, pela ausência de métodos alternativos de controle cientificamente testados (Soares et al., 2010). Tendo-se em vista os problemas enfrentados pelos produtores de cana-de-açúcar com essa praga, o fato de a espécie comportar-se como hospedeira mostrou-se como alternativa satisfatória para o manejo integrado de formigas-cortadeiras na cultura da cana-de-açúcar, especialmente em cultivo orgânico.

Crotalaria anagyroides não sobreviveu à alta incidência do fungo Colletotrichum sp., que ocasionou a morte da espécie aos 100 dias após a semeadura, o que impossibilitou a quantificação de sua massa de matéria seca aos 142 DAS. Esse ataque severo pode ter sido causado por fatores como o histórico de plantio na área de outra espécie do gênero (Crotalaria spectabilis) e mudanças no microclima em consequência do consórcio. A espécie $C$. anagyroides é descrita na literatura como hospedeira de uma ampla gama de espécies de Colletotrichum. Assim, a combinação entre a suscetibilidade e as condições ambientais favorecidas pelo consórcio, como temperatura e umidade elevadas, permitiram a expressão dos sintomas da doença (Lenné, 1992).

A baixa formação de massa de matéria seca das leguminosas, observada nas condições desse consórcio, pode ser atribuída ao momento de semeadura dessas espécies, em que a cana-de-açúcar apresentava altura de aproximadamente $1,5 \mathrm{~m}$, sombreando parcialmente as entrelinhas, e em crescimento exponencial após o fim do período de deficit hídrico. Em um sistema de consorciação, a competição interespecífica é maior pela luminosidade do que por água e nutrientes (Portes, 1984), portanto, o atraso no estabelecimento do consórcio resultante da semeadura mais tardia pode ter prejudicado o crescimento das leguminosas usadas para adubação verde.

Pesq. agropec. bras., Brasília, v.50, n.8, p.681-689, ago. 2015 DOI: $10.1590 / \mathrm{S} 0100-204 X 2015000800006$ 
A vantagem competitiva da cana-de-açúcar também pode ser destacada como razão para a supressão do desenvolvimento das leguminosas. Por ser uma espécie de metabolismo fotossintético $\mathrm{C} 4$, com rápido crescimento vegetativo e maior eficiência na assimilação de $\mathrm{C}$ atmosférico, sua capacidade em competir é superior à das espécies de metabolismo C3, como as leguminosas (Casagrande \& Vasconcelos, 2010).

Os efeitos da competição no consórcio entre cana-de-açúcar e leguminosas foram também observados por Prellwitz \& Coelho (2011). A espécie Crotalaria juncea semeada na entrelinha da primeira cana-soca, aos 44 dias após o corte, produziu massa de matéria seca superior à daquela semeada aos 51 dias após o corte, o que mostra a influência do momento de semeadura no desenvolvimento das leguminosas.

Experimentos com consórcio entre leguminosas para adubação verde e outras culturas também mostraram o efeito da competição interespecífica. Perin et al. (2004), ao testar o consórcio entre milheto e crotalária júncea, observaram que a leguminosa contribui em $65 \%$ da matéria seca acumulada, rendimento $44 \%$ inferior ao obtido em cultivo solteiro. Heinrichs et al. (2005) avaliaram o cultivo consorciado entre feijão guandu-anão e milho e obtiveram valores de massa de matéria seca entre 0,35 e 2,9 $\mathrm{Mg} \mathrm{ha}^{-1}$, em duas safras consecutivas e em momentos distintos de introdução da leguminosa.

Houve diferença significativa de massa de matéria seca de plantas daninhas nos três períodos avaliados 29, 85 e 142 DAS das leguminosas (Figura 2; Tabela 2). Aos 29 dias após a semeadura das leguminosas, observou-se a interferência dessas espécies, mesmo no estágio inicial de desenvolvimento, na incidência de plantas daninhas. Na segunda avaliação, aos 85 dias após a semeadura, constatou-se redução da massa de matéria seca de plantas daninhas, em razão da interferência das leguminosas, das quais Arachis pintoi foi a espécie que menos suprimiu as espécies invasoras. Aos 142 dias após a semeadura, todas as leguminosas testadas foram eficientes no controle de plantas daninhas em comparação às testemunhas (Tabela 2).

As plantas daninhas com maior incidência na área do experimento foram Digitaria sp., Cyperus rotundus e Eleusine indica, que representaram $49 \%$ das espécies encontradas. As demais espécies encontradas foram, em ordem decrescente: Sida sp., Conyza bonariensis, Ageratum conyzoides, Hyptis lophantha, Phyllanthus tenellus, Brachiaria plantaginea, Eragrostis pilosa, Sonchus oleraceus, Ipomoea sp., Amaranthus sp., Emilia fosbergii, Commelina benghalensis, Tridax procumbens, Chamaesyce hirta e Gnaphalium spicatum.

Severino \& Christoffoleti (2001), ao avaliar o banco de sementes do solo, observaram efeitos inibitórios do feijão guandu-anão, na emergência de plantas daninhas em cultivo solteiro. Nesse experimento, a leguminosa não havia sido cortada e incorporada ao solo, e os efeitos inibitórios foram relacionados ao tempo de convivência entre leguminosas e plantas daninhas no campo, o que coincide com os resultados do presente experimento. Fernandes et al. (1999) constataram efeitos supressivos do calopogônio solteiro sobre as plantas daninhas, com consequente redução da massa de matéria seca, fato também observado no presente experimento.

Diversos autores relataram a eficiência de Crotalaria juncea no controle de plantas daninhas. Timossi et al. (2011) avaliaram métodos de semeadura da leguminosa solteira e supressão de plantas daninhas e

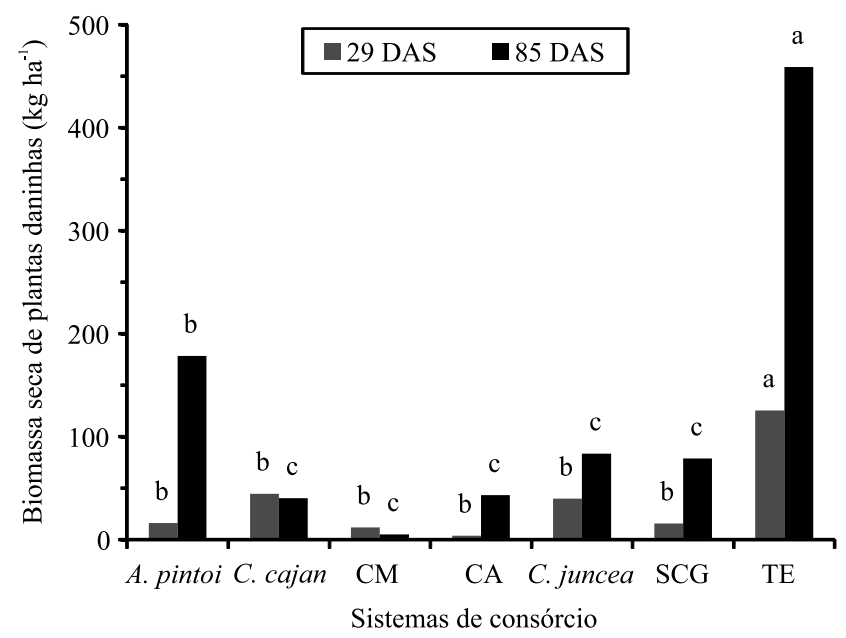

Figura 2. Massa de matéria seca de plantas daninhas, em sistemas de consórcio de cana-de-açúcar orgânica e leguminosas, aos 29 e 85 dias após a semeadura das leguminosas (DAS). Barras de cor igual, com letras iguais, não diferem entre si, pelo teste de Duncan, a 5\% de probabilidade. CM, C. muconoides; CA, C. anagyroides; SCG, Stylosanthes 'Campo Grande'; TE, testemunha sem leguminosa e sem capina. 
concluíram que houve redução do desenvolvimento da comunidade infestante. Em trabalho com consórcio de cana-de-açúcar e Crotalaria juncea, Kathiresan (2000) verificou a redução da incidência de plantas daninhas, com eficiência de controle de $43,3 \%$, somente com uma linha de semeadura da leguminosa. Os resultados obtidos no presente experimento, em que Crotalaria juncea mostrou-se eficiente na redução de massa de matéria seca de plantas daninhas, corroboram os resultados de Kathiresan (2000).

As espécies Arachis pintoi e Stylosanthes 'Campo Grande', embora tenham apresentado baixo desenvolvimento em comparação às demais espécies, foram capazes de reduzir a massa de matéria seca de plantas daninhas. Esses resultados podem ser explicados pelo potencial competitivo dessas leguminosas. $\mathrm{O}$ amendoim forrageiro destaca-se pela persistência, com os estolões enterrados no solo que viabilizam sua propagação, e pela habilidade de desenvolver-se em condições de sombreamento (Miranda et al., 2008). O gênero Stylosanthes é descrito na literatura como de ampla adaptação, resistente a pressões bióticas e abióticas e com boa capacidade de enraizamento (Barcellos et al., 2000; Cultivo..., 2007).

No consórcio com Crotalaria anagyroides, apesar de a leguminosa não ter completado o ciclo de desenvolvimento no presente experimento, em razão da incidência de doença fúngica, houve redução da incidência de plantas daninhas na avaliação aos 142 DAS. Isso se atribui às alterações promovidas pela leguminosa à dinâmica populacional de plantas daninhas, nos 100 dias iniciais, período em que a espécie

Tabela 2. Valor de p da matriz de correlação entre a massa de matéria seca de plantas daninhas, em sistemas consorciados com leguminosas, e a massa de matéria seca de plantas daninhas da testemunha sem capina e sem leguminosa, amostradas aos 142 dias após a semeadura ${ }^{(1)}$.

\begin{tabular}{lc}
\hline Sistema consorciado & $\begin{array}{c}\text { Testemunha sem capina e sem } \\
\text { leguminosa }\end{array}$ \\
\hline Testemunha sem capina e sem leguminosa & - \\
Arachis pintoi & 0,0202 \\
Cajanus cajan & 0,0139 \\
Calopogonium mucunoides & 0,0180 \\
Crotalaria anagyroides & 0,0180 \\
Crotalaria juncea & 0,0459 \\
Stylosanthes 'Campo Grande' & 0,0180
\end{tabular}

(1)Para comparação entre as amostras não pareadas, aplicou-se o teste não paramétrico de Wilcoxon-Mann-Whitney, a 5\% de probabilidade. permaneceu viva no consórcio e apresentou rápido crescimento inicial e desenvolvimento vegetativo, com consequente aumento do recrutamento de recursos do meio e da interceptação da radiação solar, o que dificultou o acesso e a utilização pelas plantas daninhas (Brighenti \& Oliveira, 2011).

O consórcio entre cana-de-açúcar orgânica e leguminosas utilizadas como adubos verdes, bem como a redução da incidência de plantas daninhas decorrente desse sistema de manejo, não interferiu significativamente na produtividade de colmos, na produção de açúcar e nos parâmetros de qualidade do caldo de cana-planta e de cana-soca.

$\mathrm{Na}$ cana-planta, os valores médios de produtividade de colmos de cana-de-açúcar e produção de açúcar foram, respectivamente, $133,7 \mathrm{Mg} \mathrm{ha}^{-1}$ e $15,4 \mathrm{Mg} \mathrm{ha}^{-1}$. Para os parâmetros de qualidade do caldo, os valores médios foram $17,9 \%$ de ${ }^{\circ}$ Brix, $90,1 \%$ de pureza, $16,2 \%$ de POL Cana e $12,5 \%$ de fibras. Na primeira cana-soca, os valores médios de produtividade de colmos de cana-de-açúcar e produção de açúcar foram, respectivamente, $108 \mathrm{Mg} \mathrm{ha}^{-1}$ e $13,4 \mathrm{Mg} \mathrm{ha}^{-1}$. Os valores médios para parâmetros de qualidade do caldo na primeira soqueira foram de 16,6 de ${ }^{\circ}$ Brix, $86,6 \%$ de pureza, $12,3 \%$ de POL Cana e $11,6 \%$ de fibras.

Os resultados do presente experimento foram contrastantes com os resultados obtidos por Resende et al. (2003), em experimento com consorciação de cana-de-açúcar. Os autores constataram que Crotalaria juncea influenciou negativamente o rendimento da cultura comercial. Assim como o trabalho supracitado, Ambrosano et al. (2013) verificaram influência negativa de Crotalaria juncea sobre a produtividade de colmos de cana-de-açúcar.

Os resultados diferem do obtido no presente experimento, em razão do período de introdução das leguminosas no consórcio. Enquanto os autores acima mencionados semearam Crotalaria juncea concomitantemente com a cana-planta ou cana-soca, no presente trabalho, a semeadura da espécie leguminosa foi realizada oito meses após o plantio da cana-de-açúcar, o que reduziu o período de convivência entre as duas espécies. Além do período de introdução, a baixa produção de massa de matéria seca das leguminosas no consórcio não interferiu no desenvolvimento da cana-de-açúcar.

Assim como o observado por Yang et al. (2013) ao avaliar o consórcio entre cana-de-açúcar e soja, no 
presente trabalho não houve efeito significativo sobre a qualidade do caldo da cana-de-açúcar. Singh \& Lal (2008), em consonância com os resultados obtidos no presente trabalho, não observaram diferenças significativas nos parâmetros de qualidade do caldo.

Os resultados do presente experimento, quanto à produção de massa de matéria seca de leguminosas, redução da incidência de plantas daninhas, produtividade de colmos de cana-de-açúcar, produção de açúcar e parâmetros do caldo de cana-de-açúcar, referem-se a uma das possibilidades de inserção das leguminosas em sistema de consórcio com cana-de-açúcar. Assim, pode subsidiar experimentos futuros sobre consórcio entre cana-de-açúcar e leguminosas para adubação verde.

\section{Conclusões}

1. As leguminosas introduzidas nas entrelinhas de cana-de-açúcar, em manejo orgânico, apresentam baixa produção de matéria seca para o sistema de consorciação com semeadura tardia dos adubos verdes.

2. Todas as leguminosas avaliadas são eficientes na redução da massa de matéria seca de plantas daninhas, no sistema de consorciação com cana-de-açúcar em manejo orgânico.

3. As leguminosas introduzidas nas entrelinhas da cana-de-açúcar, em manejo orgânico, em sistema de consorciação com semeadura tardia dos adubos verdes, não interferem na produtividade de colmos, produção de açúcar e qualidade do caldo da cana-planta e da primeira cana-soca.

\section{Agradecimentos}

À Coordenação de Aperfeiçoamento de Pessoal de Nível Superior (Capes), pela concessão de bolsa; e à Usina Goiasa, pela infraestrutura e apoio na condução do experimento.

\section{Referências}

AMABILE, R.F.; FANCELLI, A.L.; CARVALHO, A.M. de. Comportamento de espécies de adubos verdes em diferentes épocas de semeadura e espaçamentos na região dos Cerrados. Pesquisa Agropecuária Brasileira, v.359, p.47-54, 2000. DOI: 10.1590/ S0100-204X2000000100007.

AMBROSANO, E.J.; CANTARELLA, H.; ROSSI, F.; SCHAMMASS, E.A.; SILVA, E.C. da; AMBROSANO, G.M.B.; DIAS, F.L.F.; TRIVELIN, P.C.O.; MURAOKA, T. Desempenho de adubos verdes e da primeira soqueira de cana-de-açúcar cultivados consorciadamente. Revista Brasileira de Agroecologia, v.8, p.80-90, 2013.

BARCELLOS, A. de O.; ANDRADE, R.P.; KARIA, C.T.; VILELA, L. Potencial e uso de leguminosas forrageiras dos gêneros Stylosanthes, Arachis e Leucaena. In: SIMPÓSIO SOBRE MANEJO DE PASTAGEM, 17., 2000, Piracicaba. A planta forrageira no sistema de produção: anais. Piracicaba: Fealq, 2000. p.297-357

BARCELLOS, A. de O.; RAMOS, A.K.B.; VILELA, L.; MARTHA JUNIOR, G.B. Sustentabilidade da produção animal baseada em pastagens consorciadas e no emprego de leguminosas exclusivas, na forma de banco de proteína, nos trópicos brasileiros. Revista Brasileira de Zootecnia, v.37, p.51-67, 2008. DOI: 10.1590/ S1516-35982008001300008.

BRIGHENTI, A.M.; OLIVEIRA, M.F. de. Biologia de plantas daninhas. In: OLIVEIRA JR., R.S. de; CONSTANTIN, J.; INOUE, M.H. (Ed.). Biologia e manejo de plantas daninhas. Curitiba: Omnipax, 2011. p.1-36.

CASAGRANDE, A.A.; VASCONCELOS, A.C.M. Fisiologia da parte aérea. In: DINARDO-MIRANDA, L.L.; VASCONCELOS, A.C.M. de; LANDELL, M.G. de A. (Ed.). Cana-de-açúcar. Campinas: IAC, 2010. p.57-78.

CONSELHO DOS PRODUTORES DE CANA-DE-AÇÚCAR, AÇÚCAR E ÁLCOOL DO ESTADO DE SÃO PAULO. Manual de instruções. 5.ed. Piracicaba: Consecana-SP, 2006. 112p.

CULTIVO e uso do estilosantes-campo-grande. Campo Grande: Embrapa Gado de Corte, 2007. 11p. (Embrapa Gado de Corte. Comunicado técnico, 105).

ERASMO, E.A.L.; AZEVEDO, W.R.; SARMENTO, R.A.; CUNHA, A.M.; GARCIA, S.L.R. Potencial de espécies utilizadas como adubo verde no manejo integrado de plantas daninhas. Planta Daninha, v.22, p.337-342, 2004. DOI: 10.1590/ S0100-83582004000300002.

FERNANDES, M.F.; BARRETO, A.C.; EMÍDIO FILHO, J. Fitomassa de adubos verdes e controle de plantas daninhas em diferentes densidades populacionais de leguminosas. Pesquisa Agropecuária Brasileira, v.34, p.1593-1600, 1999. DOI: 10.1590/ S0100-204X1999000900009.

HEINRICHS, R.; VITTI, G.C.; MOREIRA, A.; FIGUEIREDO, P.A.M.; FANCELLI, A.L.; CORAZZA, E.J. Características químicas de solo e rendimento de fitomassa de adubos verdes e de grãos de milho, decorrente de cultivo consorciado. Revista Brasileira de Ciência do Solo, v.29, p.71-79, 2005. DOI: 10.1590/ S0100-06832005000100008.

INSTITUTO BRASILEIRO DE GEOGRAFIA E ESTATÍSTICA. Sistema IBGE de Recuperação Automática. Banco de Dados Agregados. Levantamento sistemático da produção agrícola. Disponível em: <http://www.sidra.ibge.gov.br/bda/prevsaf/default. asp>. Acesso em: $10 \mathrm{dez} .2013$.

KATHIRESAN, G. Evaluation of cultural methods of weed control in sugarcane (Saccharum officinarum). Indian Journal of Agronomy, v.45, p.804-807, 2000. 
KUVA, M.A.; GRAVENA, R.; PITELLI, R.A.; CHRISTOFFOLETI, P.J.; ALVES, P.L.C.A. Períodos de interferência das plantas daninhas na cultura da cana-de-açúcar. III - Capim-braquiária (Brachiaria decumbens) e capim-colonião (Panicum maximum). Planta Daninha, v.21, p.37-44, 2003. DOI: 10.1590/S0100-83582003000100005.

LENNÉ, J.M. Colletotrichum diseases of legumes. In: BAILEY, J.A.; JEGER, M.J. (Ed.). Colletotrichum: biology, pathology and control. Wallingford: CAB International, 1992. p.134-166.

LI, X.; MU, Y.; CHENG, Y.; LIU, X.; NIAN, H. Effects of intercropping sugarcane and soybean on growth, rhizosphere soil microbes, nitrogen and phosphorus availability. Acta Physiologiae Plantarum, v.35, p.1113-1119, 2013. DOI: 10.1007/ s11738-012-1148-y.

MIRANDA, E.M. de; SAGGIN JÚNIOR, O.J.; SILVA, E.M.R. da. Amendoim forrageiro: importância, usos e manejo. Seropédica: Embrapa Agrobiologia, 2008. 85p. (Embrapa Agrobiologia. Documentos, 259).

MONQUERO, P.A.; AMARAL, L.R.; INÁCIO, E.M.; BRUNHARA, J.P.; BINHA, D.P.; SILVA, P.V.; SILVA, A.C. Efeito de adubos verdes na supressão de espécies de plantas daninhas. Planta Daninha, v.27, p.85-95, 2009. DOI: 10.1590/ S0100-83582009000100012.

NIXON, D.J.; SIMMONDS, L.P. The impact of fallowing and green manuring on soil conditions and the growth of sugarcane. Experimental Agriculture, v.40, p.127-138, 2004. DOI: 10.1017/ S0014479703001467.

PEREIRA, G.A.M.; SILVA, D.V.; BRAGA, R.R.; CARVALHO, F.P. de; FERREIRA, E.A.; SANTOS, J.B. Fitomassa de adubos verdes e cobertura do solo na região do Alto Vale do Jequitinhonha, Minas Gerais. Revista Agro@mbiente On-line, v.6, p.110-116, 2012.

PERIN, A.; SANTOS, R.H.S.; URQUIAGA, S.; GUERRA, J.G.M.; CECON, P.R. Produção de fitomassa, acúmulo de nutrientes e fixação biológica de nitrogênio por adubos verdes em cultivo isolado e consorciado. Pesquisa Agropecuária Brasileira, v.39, p.35-40, 2004. DOI: 10.1590/ S0100-204X2004000100005.

PORTES, T.A. Aspectos ecofisiológicos do consórcio milho $\mathrm{x}$ feijão. Informe Agropecuário, v.10, p.30-34, 1984.

PRELLWITZ, W.P.V.; COELHO, F.C. Produtividade de colmos, índice de área foliar e acúmulo de $\mathrm{N}$ na soca de cana-de-açúcar em cultivo intercalar com Crotalaria juncea L. Revista Ceres, v.58, p.773-780, 2011. DOI: 10.1590/S0034-737X2011000600014.
RESENDE, A.S. de; XAVIER, R.P.; QUESADA, D.M.; URQUIAGA, S.; ALVES, B.J.R.; BODDEY, R.M. Use of green manures in increasing inputs of biologically fixed nitrogen to sugar cane. Biology and Fertility of Soils, v.37, p.215-220, 2003. DOI: 10.1007/s00374-003-0585-6.

SANTOS, H.G. dos; JACOMINE, P.K.T.; ANJOS, L.H.C. dos; OLIVEIRA, V.A. de; LUMBRERAS, J.F.; COELHO, M.R.; ALMEIDA, J.A. de; CUNHA, T.J.F.; OLIVEIRA, J.B. de (Ed.). Sistema brasileiro de classificação de solos. 3.ed. Brasília: Embrapa, 2013. 353p.

SANTOS, P.M. dos; SANTOS, A.C. dos; NEGREIROS NETO, J.V. de; ARAÚJO, A. dos S.; SILVA, J.E.C. da. Caracterização de pastagens de capins tanzânia e mombaça consorciados com estilosantes em ecótono de transição Cerrado: Floresta Amazônica. Revista Brasileira de Ciências Agrárias, v.6, p.163-173, 2011. DOI: 10.5039/agraria.v6ila817.

SEVERINO, F.J.; CHRISTOFFOLETI, P.J. Efeitos de quantidades de fitomassa de adubos verdes na supressão de plantas daninhas. Planta Daninha, v.19, p.223-228, 2001. DOI: 10.1590/ S0100-83582001000200010.

SINGH, A.K.; LAL, M. Weed management in spring planted sugarcane (Saccharum spp. hybrid)-based intercropping systems. Indian Journal of Agricultural Sciences, v.8, p.35-39, 2008.

SISTEMA de meteorologia e hidrologia do estado de Goiás. Disponível em: <http://www.simehgo.sectec.go.gov.br>. Acesso em: 2 mar. 2014.

SOARES, R.A.B.; GARCIA, J.C.; ZANATTA, G.S.C.C.; BRITO, M.C. Produção de cana orgânica. In: DINARDO-MIRANDA, L.L.; VASCONCELOS, A.C.M. de; LANDELL, M.G. de A. (Ed.). Cana-de-açúcar. Campinas: IAC, 2010. p.763-789.

STOREL JÚNIOR, A.O. A potencialidade do mercado de açúcar orgânico para a agroindústria canavieira do Estado de São Paulo. 2003. 159p. Dissertação (Mestrado) - Instituto de Economia, Universidade de Campinas, Campinas.

TIMOSSI, P.C.; WISINTAINER, C.; SANTOS, B.J. dos; PEREIRA, V.A.; PORTO, V.S. Supressão de plantas daninhas e produção de sementes de crotalária, em função de métodos de semeadura. Pesquisa Agropecuária Tropical, v.41, p.525-530, 2011. DOI: $10.5216 /$ pat.v41i4.11603.

YANG, W.; LI, Z.; WANG, J.; WU, P.; ZHANG, Y. Crop yield, nitrogen acquisition and sugarcane quality as affected by interspecific competition and nitrogen application. Field Crop Research, v.146, p.44-50, 2013. DOI: 10.1016/j. fcr.2013.03.008.

Recebido em 27 de agosto de 2014 e aprovado em 27 de maio de 2015

Pesq. agropec. bras., Brasília, v.50, n.8, p.681-689, ago. 2015 DOI: 10.1590/S0100-204X2015000800006 